\title{
PRIMARY CHARNLEY TOTAL HIP ARTHROPLASTY FOR CONGENITAL DYSPLASIA
}

\author{
EFFECT OF IMPROVED TECHNIQUES OF CEMENTING
}

TETSUNORI OKAMOTO, SHIGENORI INAO, EIJI GOTOH, MIFUMI ANDO

From Asahikawa Medical College, Japan

We performed Charnley total hip arthroplasties on 64 patients (71 hips) between 1976 and 1984 for moderate congenital acetabular dysplasia in which a superolateral cement thickness of less than $20 \mathrm{~mm}$ was expected when the cup was placed in the true acetabulum at an angle of $45^{\circ}$. Of these, 59 hips were examined 10 to 17 years after operation; 37 (group A) had been operated on between 1976 and 1982 using Charnley's original technique of cementing the acetabulum and 22 (group B) between 1983 and 1984 using more modern techniques.

In group $A$, aseptic loosening of the socket was observed in ten hips $(27.0 \%)$ and the 17-year survival rate was $81.5 \%$. In group $B$, loosening was noted in only one socket $(4.5 \%)$ and the 13-year survival rate was $100 \%$. The improved techniques produced significantly better long-term results in fixation of the cup in dysplastic hips without bone grafting.

J Bone Joint Surg [Br] 1997;79-B:83-6.

Received 28 May 1996; Accepted after revision 11 July 1996

Total hip arthroplasty for osteoarthritis secondary to congenital dysplasia of the hip presents greater technical difficulty in fixation of the cup than primary hip degeneration because of the deficiency of the acetabulum. To achieve complete coverage bone grafts have been used to supplement severe acetabular deficiency. ${ }^{1,2}$ In 1973 Charnley and Feagin $^{3}$ reported a preliminary study on the use of lowfriction arthroplasty for mild acetabular dysplasia which did not require grafts, but there has been no long-term follow-up.

T. Okamoto, MD, Senior Registrar

S. Inao, MD, Senior Registrar

E. Gotoh, MD, Assistant Professor

M. Ando, MD, Assistant Professor

Department of Orthopaedic Surgery, Asahikawa Medical College, Nishikagura 4-5, 3-11, Asahikawa 078, Japan.

Correspondence should be sent to Dr S. Inao.

C 1997 British Editorial Society of Bone and Joint Surgery 0301-620X/97/16771\$2.00
Since then there have been improvements in cementing techniques with more successful results in primary osteoarthritis and rheumatoid arthritis, ${ }^{4-6}$ but the value of these improved methods in the presence of acetabular dysplasia has not been confirmed.

We have reviewed a group of patients with acetabular dysplasia in whom a Charnley arthroplasty without bone grafting was carried out 10 to 17 years previously. We assessed the results and examined the effect of improvements in cementing technique.

\section{PATIENTS AND METHODS}

Between 1976 and 1984 we performed Charnley arthroplasties without bone grafting on 67 patients (71 hips) with congenital dysplasia of the hip.

Operative technique. Careful radiological planning was undertaken before the operation. The aim was to position the cup at the level of the true acetabulum. The hips included in the study had moderate acetabular dysplasia such that when the cup was placed in the acetabulum at an angle of $45^{\circ}$ the thickness of the superior cement mantle was less than $20 \mathrm{~mm}$ (Fig. 1). Between 1976 and 1982, 45 hips were operated on using the original acetabular cementing technique ${ }^{7}$ (group A). From 1983 to 1984 we used an improved cementing technique in 26 hips (group B). In these cases the subchondral bone was retained by transverse acetabular deepening, a flanged socket was used, multiple small anchoring holes were made and pressurised lavage undertaken. In stem fixation the original cementing technique was used in many cases in group A, but in group B a cement gun, an intramedullary bone plug, pulsatile lavage and other modifications in technique were employed.

In group A, three patients (three hips) died less than ten years after operation, three hips developed deep infection, one was revised because of recurrent dislocation and one was lost to follow-up. The remaining 37 hips were examined at a mean of 13.6 years after surgery (10 to 17). There were 35 women and two men with a mean age at operation of 61 years (44 to 76) and a mean weight of $52 \mathrm{~kg}$ (38 to 72). According to the classification of Crowe, Mani and Ranawat $^{8} 28$ hips were in group I, eight in group II and one in group III. 


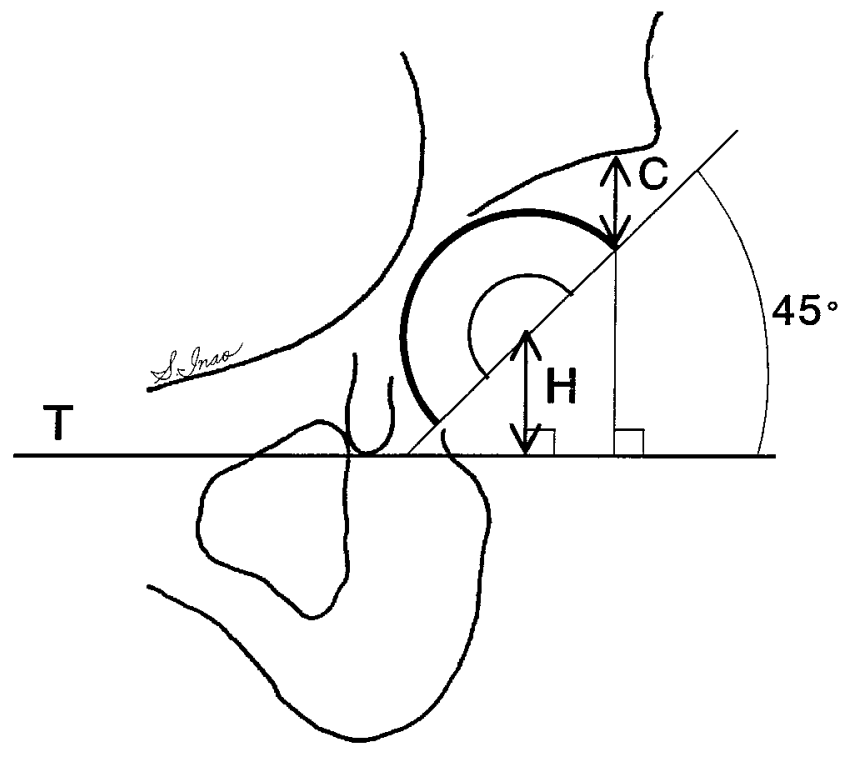

Fig. 1

Diagram showing the preoperative estimation of the degree of acetabular dysplasia. A Charnley small socket template of $40 \mathrm{~mm}$ diameter, which is suitable for most Japanese patients, is superimposed on an anteroposterior radiograph of the hip at the level of the true acetabulum. The template is placed in $45^{\circ}$ of inclination with $20 \mathrm{~mm}$ of socket height and with the most medial border on the true outer wall of the acetabulum. The height of the socket centre $(\mathrm{H})$ is determined by measuring the vertical distance between the centre and the interteardrop line $(T)$ which connects the most distal points of the teardrops on both sides. Acetabular dysplasia was classified by the expected thickness of the superolateral cement (C) into low (less than $20 \mathrm{~mm}$ ) and high $(20 \mathrm{~mm}$ or more) groups.

In group B, four patients (four hips) died less than ten years after operation. The remaining 22 (20 women and two men) were examined at a mean of 10.5 years (10 to 13 ) after surgery. Their mean age at operation was 63 years (53 to 72 ) and their mean weight was $55 \mathrm{~kg}$ (38 to 67). Using the Crowe classification 18 hips were in group I, three in group II and one in group III. The clinical results were assessed by the modified Merle d'Aubigné and Postel scoring system. ${ }^{9}$ Radiologically, type- 3 or type- 4 demarcation of the socket, as defined by Hodgkinson, Shelley and Wroblewski, ${ }^{10}$ and definite or probable loosening of the stem using the criteria of Harris, McCarthy and O'Neill ${ }^{11}$ were classified as aseptic loosening.

\section{RESULTS}

Clinical results (Table I). Excellent pain relief was maintained. The average pain scores were 5.6 in group A and 5.9 in group B at the latest follow-up. Two hips in group A had significant pain (grade 4) without evidence of aseptic loosening. All other hips had either no pain (grade 6) or only slight pain (grade 5) regardless of the radiological findings. Walking ability and the range of movement tended to deteriorate. The average scores in walking ability were 4.3 in group A and 4.9 in group B when last reviewed. Walking ability of grade 4 or less was noted in 19 patients, 13 in group A and six in group B, due to severe thoracolumbar kyphosis in five, osteoarthritis in the opposite hip in five, hemiplegia due to cerebral infarction in three, osteoarthritis of the knee in one, lumbar canal stenosis in one, aplastic anaemia in one and other causes in three. The average scores for range of movement were 4.3 in group A and 4.9 in group B.

Radiological findings. Radiographs showed a gradual increase in the rate of aseptic loosening from five years after operation. Of the 37 hips in group A loosening of the cup was noted in eight $(21.6 \%)$ at five years, in nine $(24.3 \%)$ at ten years and in ten $(27.0 \%)$ at the latest followup when type- 3 and type- 4 demarcation was noted in seven and three hips, respectively. In the 22 hips in group B only one type-3 loosening was seen which appeared ten years after operation. Thus, at the latest follow-up 11 of the 59 hips $(18.6 \%)$ showed loosening (Table II, Figs 2 and 3).

In group A loosening of the stem was noted in four hips $(10.8 \%)$ at five years and in five hips $(13.5 \%)$ both at ten years and at the latest review. In group B the stem was loose by five years in one hip and in two at ten years and when last seen, giving seven out of 59 hips (11.9\%).

No evidence of osteolysis was seen around the cup even in the presence of aseptic loosening. Focal osteolysis was noted around the stem in seven of the 59 hips (11.9\%), five in group A and two in group B. Only two were associated with aseptic loosening. Catastrophic polyethylene wear with more than $3 \mathrm{~mm}$ of superior migration of the femoral head within the socket has not been seen. The age and weight of the patients had no relation to the presence of osteolysis.
Table I. Clinical results in both groups showing scores for pain, walking, and range of movement (ROM) Charnley (1972)

\begin{tabular}{llll}
\hline Group & $\mathbf{5} \mathbf{~ y r}$ & $\mathbf{1 0} \mathbf{~ y r}$ & Latest follow-up \\
\hline A (n=37) & & & \\
$\quad$ Pain & 5.8 & 5.7 & 5.6 \\
Walking & 5.1 & 4.8 & 4.3 \\
ROM & 4.8 & 4.4 & 4.3 \\
B (n=22) & & & \\
$\quad$ Pain & 5.7 & 6.0 & 5.9 \\
$\quad$ Walking & 5.4 & 5.1 & 4.9 \\
ROM & 4.9 & 4.8 & 4.9 \\
\hline
\end{tabular}

Table II. Radiological appearance of the cup at the latest follow-up in both groups, by number and percentage

\begin{tabular}{lcc}
\hline \multirow{2}{*}{ Hodgkinson type } & \multicolumn{2}{l}{ Group } \\
\cline { 2 - 3 } & $\mathbf{A}$ & \multicolumn{1}{c}{ B } \\
\hline 0 & $7(18.9)$ & $9(40.9)$ \\
1 & $9(24.3)$ & $10(45.5)$ \\
2 & $11(29.7)$ & $2(9.1)$ \\
3 & $7(18.9)$ & $1(4.5)$ \\
4 & $3(8.1)$ & $0(0.0)$ \\
\hline
\end{tabular}




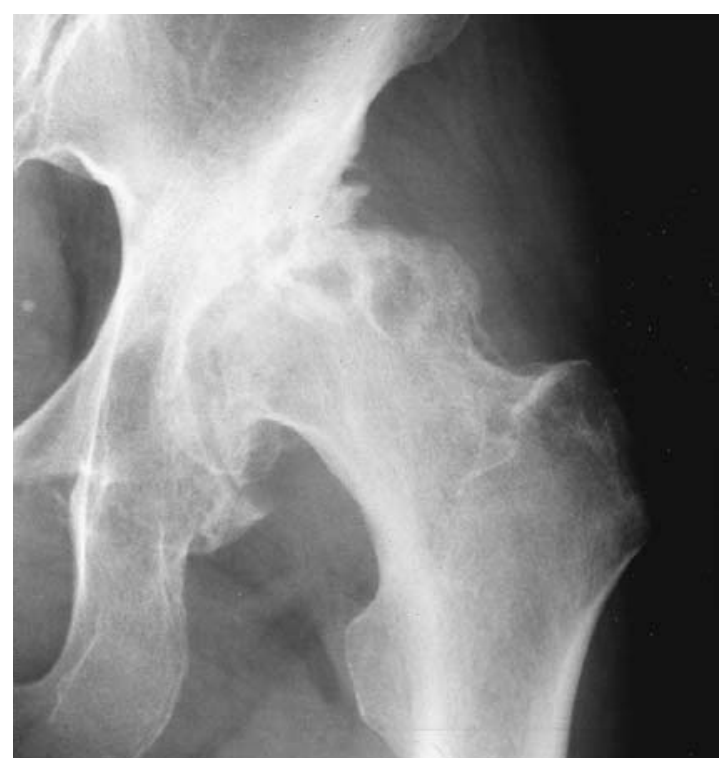

Fig. 2a

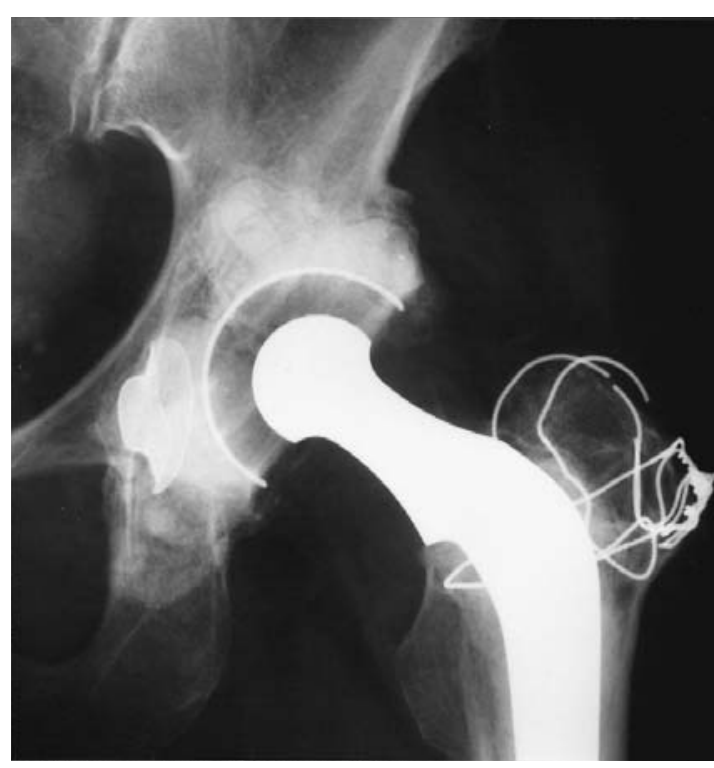

Fig. 2b

Radiographs of a patient in group A taken (a) before operation, and (b) 13 years after total hip arthroplasty. The superolateral cement thickness was $13 \mathrm{~mm}$. Type-3 demarcation of the socket is observed.

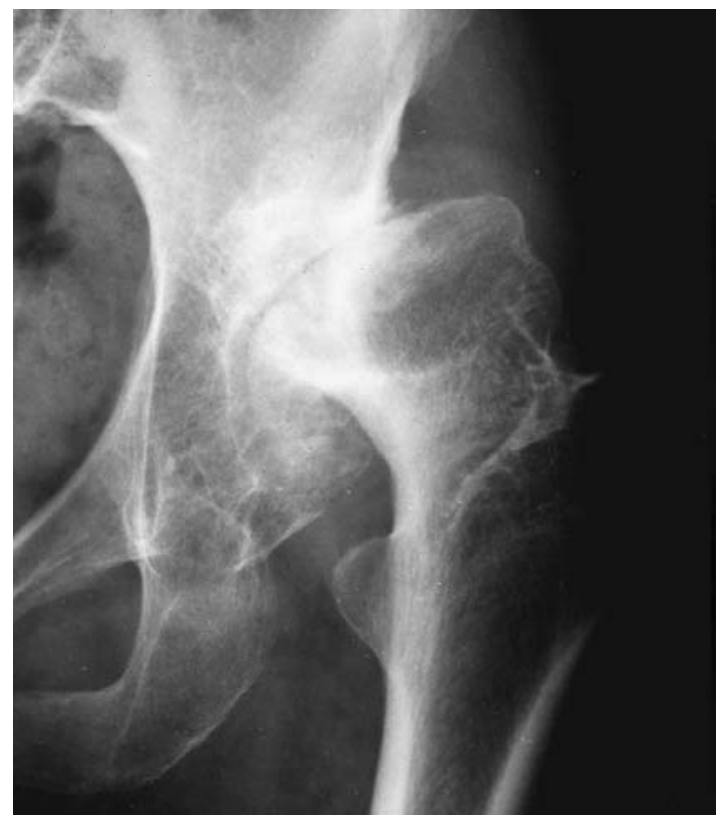

Fig. 3a

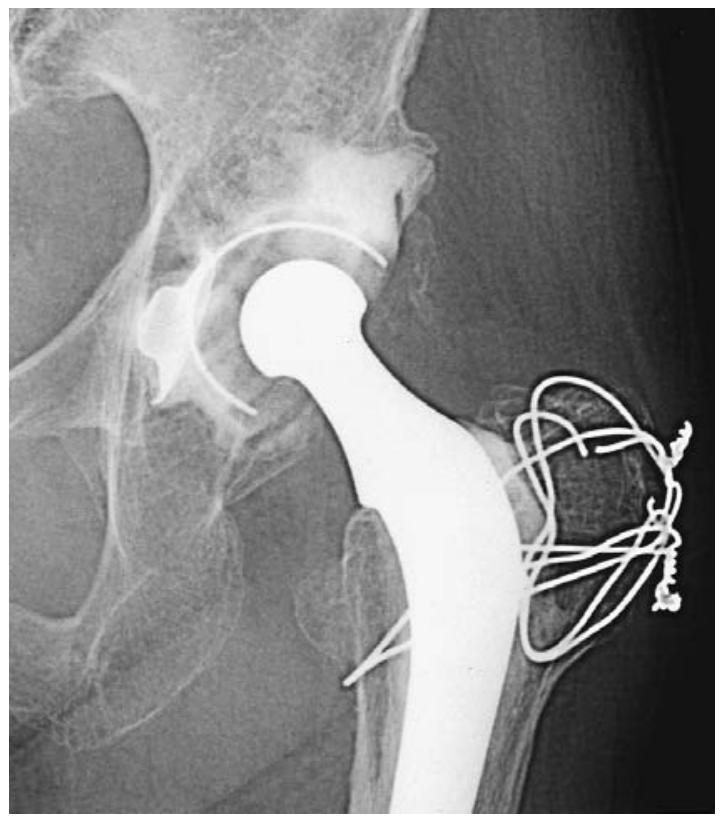

Fig. $3 b$

Radiographs of a patient in group B taken (a) before operation, and (b) 11 years after total hip arthroplasty. The superolateral cement thickness was $18 \mathrm{~mm}$. There are no radiological signs of loosening.

No hip has been revised because of aseptic loosening. Survival analysis. We performed survival analysis as described by Dobbs. ${ }^{12}$ The point of failure was defined as: revision or removal of implants for any reason; impending revision due to progressive aseptic loosening; complaint of significant pain (grade 4 or less); and loss to follow-up. Non-progressive aseptic loosening without significant pain was not assessed as a failure. The latest information available before death was used in the patients who had died less than ten years after operation.

The survival rate was $88.5 \%$ at 10 years and $81.5 \%$ at 17 years in group A, and was $100 \%$ both at 10 and 13 years in group B.

\section{DISCUSSION}

The anatomical abnormality found in acetabular dysplasia gives technical problems in obtaining sound fixation of the 
cup in the true acetabulum ${ }^{13}$ and complete bony coverage cannot usually be achieved without placing it in considerable abduction. If the prosthesis is placed in the ideal position of $45^{\circ}$ abduction the superolateral cement mantle is inevitably thickened.

The long-term results with the Charnley arthroplasty using the original techniques have shown an incidence of loosening of the cup of $14 \%$ to $33 \% 15$ years after operation. ${ }^{14-17}$ These studies included various diseases of the hip and were based on rates of follow-up of only $50 \%$ to $65 \%$. We focused on hips with moderate acetabular dysplasia and achieved follow-up in $99 \%$ of the patients. The incidence of loosening in our group A using the original Charnley technique was also high at $27.0 \%$ at a mean of 13.6 years after operation.

With the newer techniques of cementing of the acetabular prosthesis there has been a dramatic improvement in the results at five and ten years. ${ }^{4-6,18}$ Our study also shows significant improvement when using these methods; we consider that the use of a flanged socket allows effective pressurisation of the cement even in the presence of acetabular deficiency. We have not found a significant change in the rate of loosening in the stem when using the improved techniques. Dysplastic hips often show excessive anteversion and hypoplasia of the femoral neck; these deformities of the proximal femur give rise to difficulty in placing the implant and may have a significant influence on long-term fixation.

In the survival analysis of long-term studies the criteria of failure have not been consistent. Revisions have been generally used as the point of failure, and there is no agreement whether the presence of significant pain or loss to follow-up should be regarded as a failure. Murray, Carr and Bulstrode ${ }^{19}$ suggested that the development of significant pain without radiological evidence of loosening should be classed as partial failure, and Scuderi and Insall ${ }^{20}$ emphasised that cases lost to follow-up should also be considered as failures.

Russotti and Harris ${ }^{21}$ placed the cup proximally in the false acetabulum to avoid a thick cement mantle. Their long-term review showed an aseptic loosening rate of $16 \%$ after 11 years. We consider that maximal preservation of acetabular bone stock is of advantage in case a revision operation is required.

Recently, Mackenzie, Kelley and Johnston ${ }^{22}$ reported a 10- to 21-year follow-up in prostheses with a thick layer of cement in severe dysplastic hips without bone grafting and found a relatively high rate of $26 \%$ for aseptic loosening of the socket. In our opinion reconstruction of the acetabular bone stock by autogenous bone grafting is a better procedure in severe dysplastic hips when placement of the cup at $45^{\circ}$ in the true acetabulum would give a thickness of superolateral cement of $20 \mathrm{~mm}$ or more ${ }^{2}$ (Fig. 1).

We consider that the Charnley total hip arthroplasty provides stable long-term fixation of the cup in the presence of moderate acetabular dysplasia without bone grafting when current techniques of cementing are used.

We thank Professor Y. Takemitsu, MD, for his encouragement of this study.

No benefits in any form have been received or will be received from a commercial party related directly or indirectly to the subject of this article.

\section{REFERENCES}

1. Harris WH, Crothers O, Oh I. Total hip replacement and femoralhead bone-grafting for severe acetabular deficiency in adults. $J$ Bone Joint Surg [Am] 1977;59-A:752-9.

2. Inao S, Gotoh E, Ando M. Total hip replacement using femoral neck bone to graft the dysplastic acetabulum: follow-up study of 18 patients with old congenital dislocation of the hip. J Bone Joint Surg [Br] 1994;76-B:735-9.

3. Charnley J, Feagin JA. Low-friction arthroplasty in congenital subluxation of the hip. Clin Orthop 1973;91:98-113.

4. Ranawat CS, Rawlins BA, Harju VT. Effect of modern cement technique on acetabular fixation total hip arthroplasty: a retrospective study in matched pairs. Orthop Clin North Am 1988;19:599-603.

5. Kobayashi S, Terayama K. Radiology of low-friction arthroplasty of the hip: a comparison of socket fixation techniques. J Bone Joint Surg [Br] 1990;72-B:439-43.

6. Önsten I, Besjakov J, Carlsson ÅS. Improved radiographic survival of the Charnley prosthesis in rheumatoid arthritis and osteoarthritis: results of new versus old operative techniques in 402 hips. J Arthroplasty 1994;9:3-8.

7. Charnley J. Hip sockets - theory. In: Charnley J. Low friction arthroplasty of the hip. New York: Springer-Verlag, 1979:91-106.

8. Crowe JF, Mani VJ, Ranawat CS. Total hip replacement in congenital dislocation and dysplasia of the hip. J Bone Joint Surg [Am] 1979;61-A:15-23.

9. Charnley J. The long-term results of low-friction arthroplasty of the hip performed as a primary intervention. J Bone Joint Surg $[\mathrm{Br}]$ 1972;54-B:61-76.

10. Hodgkinson JP, Shelley P, Wroblewski BM. The correlation between the roentgenographic appearance and operative findings at the bonecement junction of the socket in Charnley low friction arthroplasty. Clin Orthop 1988;228:105-9.

11. Harris WH, McCarthy JC Jr, O'Neill DA. Femoral component loosening using contemporary techniques of femoral cement fixation. J Bone Joint Surg [Am] 1982;64-A:1063-7.

12. Dobbs HS. Survivorship of total hip replacements. J Bone Joint Surg [Br] 1980;62-B:168-73.

13. Schüller HM, Dalstra M, Huiskes R, Marti RK. Total hip reconstruction in acetabular dysplasia: a finite element study. $J$ Bone Joint Surg $[\mathrm{Br}]$ 1993;75-B:468-74.

14. Wroblewski BM. 15-21-year results of the Charnley low-friction arthroplasty. Clin Orthop 1986;211:30-5.

15. McCoy TH, Salvati EA, Ranawat CS, Wilson PD Jr. A fifteen-year follow-up study of one hundred Charnley low-friction arthroplasties. Orthop Clin North Am 1988;19:467-76.

16. Welch RB, McGann WA, Picetti III GD. Charnley low-friction arthroplasty: a fifteen- to seventeen-year follow-up study. Orthop Clin North Am 1988;19:551-5.

17. Kavanagh BF, Dewitz MA, Ilstrup DM, Stauffer RN, Coventry MB. Charnley total hip arthroplasty with cement: fifteen-year results. J Bone Joint Surg [Am] 1989;71-A:1496-503.

18. Kobayashi S, Eftekhar NS, Terayama K, Iorio R. Risk factors affecting radiological failure of the socket in primary Charnley low friction arthroplasty: a 10- to 20-year follow-up study. Clin Orthop 1994;306:84-96.

19. Murray DW, Carr AJ, Bulstrode C. Survival analysis of joint replacements. J Bone Joint Surg [Br] 1993;75-B:697-704.

20. Scuderi GR, Insall JN. Letter. Survival analysis. J Bone Joint Surg [Br] 1994;76-B:507-8.

21. Russotti GM, Harris WH. Proximal placement of the acetabular component in total hip arthroplasty: a long-term follow-up study. J Bone Joint Surg [Am] 1991;73-A:587-92.

22. MacKenzie JR, Kelley SS, Johnston RC Total hip replacement for coxarthrosis secondary to congenital displasia and dislocation of the hip. I Bone Joint Surg [Am] 1996;78-A:55-61. 